\section{Optimized sensitivity of allele-specific PCR for prenatal typing of human platelet alloantigen single nucleotide polymorphisms}

\author{
P. Bugert ${ }^{1}$, A. Lese' ${ }^{1}$ J. Meckies², W. Zieger ${ }^{2}$, H. Eichler ${ }^{1}$, and H. Klüter ${ }^{1}$ \\ ${ }^{1}$ Red Cross Blood Service of Baden-Württemberg-Hessen, and ${ }^{2}$ University of \\ Heidelberg, Mannheim, Germany
}

BioTechniques 35:170-174 (July 2003)

PCR using sequence-specific primers (PCR-SSP) is widely employed for the genotyping of single nucleotide polymorphisms (SNPS) in both routine diagnosis and medical research. The human platelet alloantigens (HPAs) represent SNPS in platelet-specific glycoproteins, and HPA-1, -2, -3, and -5 are the most relevant in immunohematology. In most protocols, the respective HPA-SNPs are analyzed in allele-specific reactions, each with at least $100 \mathrm{ng}$ DNA. In many cases, prenatal HPA typing in the diagnosis of neonatal alloimmune thrombocytopenia is often limited by the restricted amounts of fetal DNA that are obtainable. We developed a novel PCR-SSP technique to achieve accurate HPA genotypes using only $1 \mathrm{ng}$ $D N A$ per reaction. The concentration of HPA-specific primers was increased to $1 \mu M$ each and exhibited a higher sensitivity compared to a commercial PCR-SSP kit. The modified PCR-SSP technique enabled the identification of fetal HPA genotypes using only $0.5 \mathrm{~mL}$ amniotic fluid (from week 16 of gestation) and from a maternal plasma sample (from week 38 of gestation). The principle of the modified PCR-SSP technique may also be applied for the genotyping of other SNPS from limited amounts of DNA.

\section{INTRODUCTION}

Genotyping for single nucleotide polymorphisms (SNPs) is relevant to various research fields and in routine diagnosis. Today, allele-specific PCR amplification techniques using sequence-specific primers (PCR-SSP) are widely employed $(1,2)$. For the typing of an SNP, two PCRs are needed, each containing an allele-specific primer and a common primer. After PCR and agarose gel electrophoresis, the genotyping result is evaluated by the presence or absence of an allelespecific PCR product. Compared to other techniques, PCR-SSP is rather DNA consuming because at least 100 ng genomic DNA are needed for each reaction. Other typing methods, such as PCR with allele-specific oligonucleotide (PCR-ASO) hybridization or with oligonucleotide ligation assay (PCR-OLA), can be carried out with much less DNA because the target sequences are amplified in a single multiplex PCR. However, these methods are more time-consuming, and addi- tional reagents and laboratory equipment are needed.

Alloantigens primarily represent SNPs in the genes that encode immunogenic proteins. The status of alloantigens, such as human leukocyte antigens (HLAs), blood group antigens, or human platelet alloantigens (HPAs), is frequently investigated before organ transplantation or blood transfusion. Alloreactive antibodies against HPA may cause thrombocytopenic syndromes such as neonatal alloimmune thrombocytopenia (NAIT) and posttransfusion purpura (PTP). The most relevant antigens in Caucasian populations are HPA-1, $-2,-3$, and -5 (3). In a clinical environment, the rapid and accurate typing for the HPAs of patients and platelet donors is mandatory for patients supplied with HPA-matched platelet products. In the case of NAIT, typing the father provides important information on the risk of future pregnancies. Various PCR-based techniques have been described for the genotyping of the HPA-1, -2, -3, and -5 SNPs (2), and PCR-SSP is most commonly used
(4-7). Clinical samples such as whole blood samples from patients with low leukocyte counts or amniotic fluid from early weeks of gestation often contain limited amounts of DNA, and PCR-SSP typing does not provide reliable results.

Here we report a modified PCR-SSP technique suitable for the genotyping of SNPs from samples with low DNA content. We used the HPA-1, $-2,-3$, and -5 SNPs as a model. The optimal range of DNA amount per reaction was estimated by investigating dilution series of DNA.

\section{MATERIALS AND METHODS}

DNA Isolation from Reference Blood Samples and Clinical Samples

Blood samples from four individuals that had been previously HPA genotyped by sequencing of the SNP loci, representing the different allelic combinations, served as a reference. For the isolation of genomic DNA from $200 \mu \mathrm{L}$ whole blood, we used the QIAamp ${ }^{\circledR}$ DNA Blood Mini Kit (Qiagen, Hilden, Germany) according to the manufacturer's standard protocol. The DNA concentration was estimated from the absorbance at $260 \mathrm{~nm}$ using a UV-spectrophotometer (GeneQuant ${ }^{\mathrm{TM}}$ pro; Amersham Biosciences, Freiburg, Germany). From the reference samples, we obtained 20-60 ng DNA/ $\mu \mathrm{L}$ whole blood.

Plasma, amniotic fluid (especially obtained in early weeks of gestation), or buccal swabs represent clinical samples with potentially low DNA content. For this investigation, the clinical samples were provided by the Department of Obstetrics and Gynecology, University of Heidelberg, Faculty of Clinical Medicine Mannheim, after written consent. Amniotic fluid $(0.5 \mathrm{~mL})$ samples were taken from two women in week 16 of gestation. The amniotic cells were centrifuged for $5 \mathrm{~min}$ at $3000 \times \mathrm{g}$ and resuspended in $200 \mu \mathrm{L}$ phosphate-buffered saline (PBS) buffer. For DNA isolation, the same procedure as used for whole blood samples was carried out, except that we used only $50 \mu \mathrm{L}$ elution buffer to recover the DNA from the spin columns. The absorbance at $260 \mathrm{~nm}$ revealed DNA concentrations of approxi- 
Table 1. Primer Sequences and Concentrations Used in PCR-SSP Genotyping for HPA-1, -2, -3, and -5

\begin{tabular}{|c|c|c|c|}
\hline $\begin{array}{l}\text { Primer } \\
\text { Code }\end{array}$ & Primer Sequence & $\begin{array}{l}\text { Primer } \\
\text { centration } \\
(\mu \mathrm{M})\end{array}$ & $\begin{array}{c}\text { Product } \\
\text { Size } \\
\text { (bp) }\end{array}$ \\
\hline HPA-1a & 5'-GACTTACAGGCCCTGCCTCT-3' & 1 & 190 \\
\hline HPA-1b & 5'-ACTTACAGGCCCTGCCTCC-3' & 1 & 189 \\
\hline HPA-1reva & 5'-GTGCAATCCTCTGGGGAC-3' & 1 & \\
\hline HPA-2a & 5'-CCCCCAGGGCTCCTGAC-3' & 1 & 241 \\
\hline HPA-2b & 5'-CCCCCAGGGCTCCTGAT-3' & 1 & 241 \\
\hline HPA-2rev & 5'-GCCAGCGACGAAAATAGAGG-3' & 1 & \\
\hline HPA-3a & 5'-GGACTGGGGGCTGCCCAT-3' & 1 & 214 \\
\hline HPA-3b & 5'-TGGACTGGGGGCTGCCCAG-3' & 1 & 215 \\
\hline HPA-3rev & 5'-ACAGCACACCCGGACCCC-3' & 1 & \\
\hline HPA-5a & 5'-GAAGGAAGAGTCTACCTGTTTACTATCAAAG-3' & 1 & 258 \\
\hline HPA-5b & 5'-AAGGAAGAGTCTACCTGTTTACTATCAAAA-3' & 1 & 257 \\
\hline HPA-5rev & 5'-CTCTCATGGAAAATGGCAGTA-3' & 1 & \\
\hline$\beta$-glob-Fb & 5'-GGTTGGCCAATCTACTCCCAGG-3' & 0.1 & 536 \\
\hline$\beta$-glob-R & 5'-GCTCACTCAGTGTGGCAAAG-3' & 0.1 & \\
\hline
\end{tabular}

mately $2 \mathrm{ng} / \mu \mathrm{L}$ in both samples. Approximately $1 \mathrm{~mL}$ plasma was obtained from the EDTA blood samples of four females before cesarean section. The standard protocol for the DNA isolation was adapted to a $1-\mathrm{mL}$ sample volume, and DNA elution was performed in 50 $\mu \mathrm{L}$ buffer. The absorbance at $260 \mathrm{~nm}$ revealed DNA concentrations up to 4 $\mathrm{ng} / \mu \mathrm{L}$. DNA was also isolated from maternal leukocytes and corresponding umbilical cord blood samples as a source of fetal DNA.

Additionally, buccal swab samples of eight volunteer donors represented a third source with limited amounts of DNA. A standard protocol for the DNA isolation from buccal swabs was provided by the manufacturer of the DNA isolation kit and performed without modifications. The absorbance at 260 $\mathrm{nm}$ of the DNA solutions revealed amounts of 300-600 ng total DNA at concentrations of $2-4 \mathrm{ng} / \mu \mathrm{L}$.

PCR-SSP Genotyping for HPA-1, -2, -3 , and -5

Reactions of the modified PCR-SSP technique were carried out in a total volume of $10 \mu \mathrm{L}$. To reduce error rates caused by multiple pipetting steps, we prepared eight primer mixtures specific for the typing of the HPA-1ab, -2ab,
$-3 a b$, and -5ab alleles. Each primer mixture contained $2 \mu \mathrm{M}$ each of the allelespecific forward and common reverse primer and $0.2 \mu \mathrm{M}$ each of the internal control ( $\beta$-globin gene) primers (Table $1)$. Synthetic oligonucleotide primers were synthesized by MWG-Biotech AG (Ebersberg, Germany). Other PCR reagents were prepared as $10 \times$ concentrates: (i) $10 \times$ PCR buffer contained 100 $\mathrm{mM}$ Tris-HCl, $\mathrm{pH}$ 8.3, $500 \mathrm{mM} \mathrm{KCl}, 15$ $\mathrm{mM} \mathrm{MgCl}$, and $0.1 \%$ bovine serum albumin (BSA); (ii) 10× dNTPs contained $2 \mathrm{mM}$ each deoxynucleotide; (iii) $10 \times$ gel loading buffer contained $50 \%$ glycerol and $1 \mathrm{mg} / \mathrm{mL}$ cresol red. A readyto-use reaction mixture was prepared by mixing equal volumes of each of the three $10 \times$ reagents and was named the red buffer mixture (RBX). Aliquots of the RBX could be stored at $-20^{\circ} \mathrm{C}$ for at least 1 year without affecting the quality of the PCR results. The setup of the reactions was performed according to the protocol of a commercial PCR-SSP kit (HPA-SSP; Innotrain, Kronberg, Germany). The primer mixtures were dispensed in $5 \mu \mathrm{L}$ into the $0.2 \mathrm{~mL}$ PCR tubes (8-tube strips or 96-well plates were used). For each sample, a PCR master mixture was prepared that contained $18 \mu \mathrm{L}$ DNA solution, $26.3 \mu \mathrm{L}$ $\mathrm{RBX}$, and $0.7 \mu \mathrm{L}$ Taq DNA polymerase (5 U/ $\mu \mathrm{L}$; Qiagen). Five microliters of 
master mixture were dispensed into each primer mixture. Thus, each of the eight reactions contained $2 \mu \mathrm{L}$ DNA solution, $1 \mu \mathrm{M}$ each of the HPA-specific primers, $0.1 \mu \mathrm{M}$ each of the internal control primers, $10 \mathrm{mM}$ Tris- $\mathrm{HCl}, 50$ $\mathrm{mM} \mathrm{KCl}, 1.5 \mathrm{mM} \mathrm{MgCl} 2,0.01 \%$ BSA, $5 \%$ glycerol, $0.1 \mathrm{mg} / \mathrm{mL}$ cresol red, and 0.4 U Taq DNA polymerase.

To compare the results, all DNA samples were HPA typed in parallel using the HPA-SSP kit. The kit's primer mixtures contained $0.2 \mu \mathrm{M}$ each of HPA-specific primer and $0.03 \mu \mathrm{M}$ each of the control primers (human growth hormone locus, $434 \mathrm{bp}$ ). The PCR was carried out according to the manufacturer's protocol with no modifications. Our modified PCR-SSP was performed with the following cycling program: a 2 -min initial denaturation at $95^{\circ} \mathrm{C}$, followed by 10 cycles of $15 \mathrm{~s}$ denaturation at $95^{\circ} \mathrm{C}$ and $1 \mathrm{~min}$ annealing/extension at $66^{\circ} \mathrm{C}$, followed by 20 cycles of $15 \mathrm{~s}$ denaturation at $95^{\circ} \mathrm{C}, 1 \mathrm{~min}$ annealing at $62^{\circ} \mathrm{C}$, and $30 \mathrm{~s}$ extension at $72^{\circ} \mathrm{C}$. The amplification products were separated on $2 \%$ agarose gels containing 0.5 $\mathrm{ng} / \mathrm{mL}$ ethidium bromide in a rapid agarose gel electrophoresis (RAGE ${ }^{\circledR}$; Cascade Biologics, Portland, OR, USA) chamber for $5 \mathrm{~min}$ at $25 \mathrm{~V} / \mathrm{cm}$. The results were obtained by a visual inspection of the gels and documented using a UV documentation device with charge-coupled device (CCD) camera (UVP, Upland, CA, USA).

\section{RESULTS AND DISCUSSION}

\section{Validation of the PCR-SSP Method}

First-line validation was carried out by genotyping four reference samples that represented the three genotype variants for each SNP. Our modified PCR-SSP technique confirmed the genotypes of the reference samples (i.e., DNA1, HPA-1bb 2ab 3ab 5aa; DNA2, HPA-1aa 2aa 3aа 5aa; DNA3, HPA-1aa 2aa 3aa 5bb; and DNA4, HPA-1aa 2bb 3ab 5ab) (Figure 1). An additional amplification product of unknown origin was consistently found in the HPA-3b reaction. Because of its size, the PCR product could be easily distinguished from the internal control and the allele-specific PCR products.
The validation experiments were performed with $20 \mathrm{ng}$ genomic DNA per PCR; thus, 160 ng DNA were needed for complete HPA genotyping. Additional validation of the technique could be achieved by the retyping of 92 blood donor samples that had been genotyped previously for HPA-1, $-2,-3$, and -5 using a commercial PCR-SSP kit. The modified PCR-SSP technique confirmed the HPA genotypes in all 92 samples (data not shown).

The primer sequences used in our modified PCR-SSP technique are similar to those supplied with the commercial kit and published previously (4-7), with slight modifications. The most significant difference was the increased primer concentrations ( $1 \mu \mathrm{M}$ each HPA-specific oligonucleotides) compared to the commercial kit $(0.2 \mu \mathrm{M})$ and to published protocols $(4,6,7)$.

\section{Estimation of the Optimal Range of DNA Concentration}

The amount of template DNA is one of the most important parameters defining the specifity of the PCR-SSP techniques. Most of the published protocols suggest the use of 50-250 ng DNA per PCR (reviewed in Reference
2). To estimate the optimal range of DNA concentration for the modified PCR-SSP technique, we tested a linear dilution series of the four reference DNA samples with $125,25,5,1,0.2$, and 0.04 ng per reaction. Unambigous results could be obtained using 1-25 ng DNA per reaction (Figure 2). Higher amounts of DNA led to weak, unspecific amplification in the PCRs that was thought to be negative. Below 1 ng DNA per PCR, the DNA bands on the agarose gel were too weak for reliable reading of the typing results. With the use of a commercial PCR-SSP system, accurate typing results could only be achieved when $25 \mathrm{ng}$ or more DNA were amplified per reaction (Figure 2). This was in accordance with the manufacturer's suggestion of $100 \mathrm{ng}$ DNA per reaction.

Approximately 1 ng DNA per reaction was sufficient for accurate typing. Thus, a total of less than $10 \mathrm{ng}$ DNA is required for PCR-SSP typing for HPA$1,-2,-3$, and -5 , which is comparable to other techniques such as PCR-ASO or PCR-OLA (reviewed in Reference 2). To use the modified protocol in routine HPA genotyping, the concentration of the DNA solutions should be approximately $10 \mathrm{ng} / \mu \mathrm{L}$.

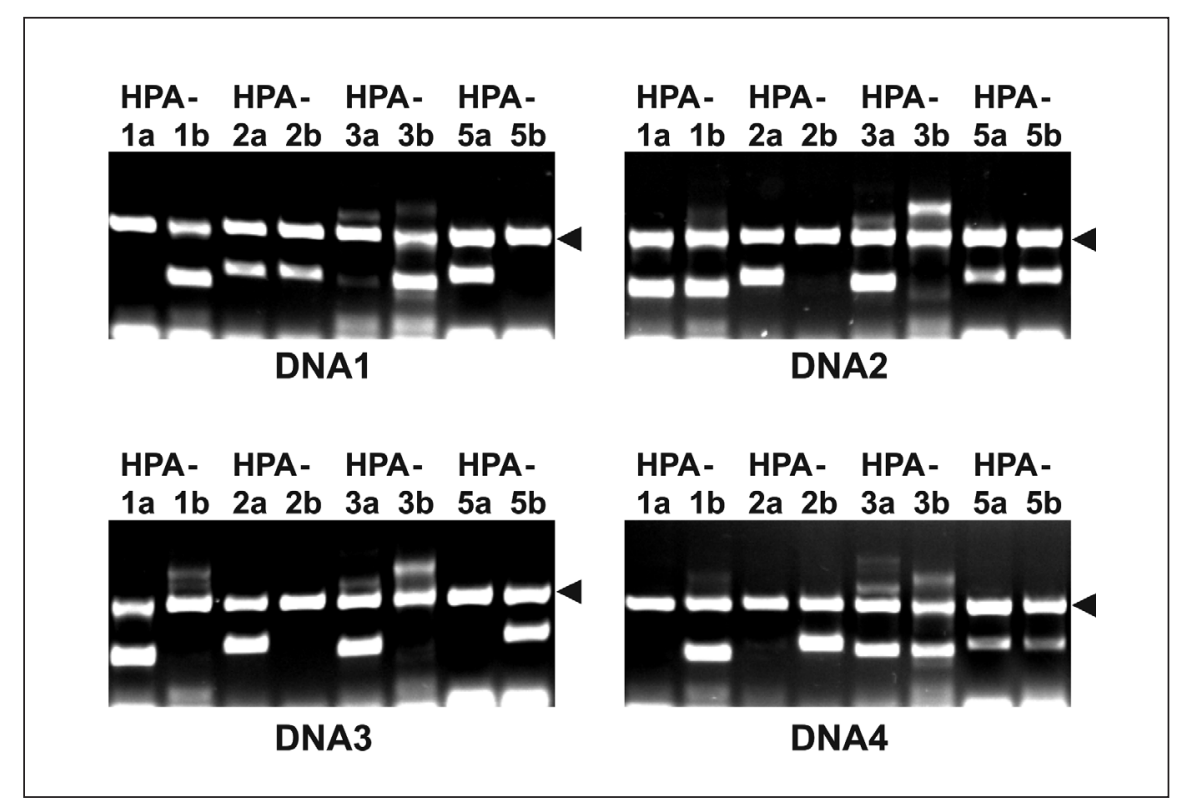

Figure 1. Validation of the PCR-SSP technique by typing four reference DNA samples. Genotyping results were as expected: HPA-1bb -2ab -3bb -5aa for DNA1; HPA-1ab -2aa -3aa -5ab for DNA2; HPA -1aa -2aa -3aa -5bb for DNA3; and HPA-1bb -2bb -3ab and -5ab for DNA4. The amplification product (536 bp) of the internal control is marked by an arrowhead. Twenty nanograms of template DNA were used per reaction. 
A

HPA- HPA- HPA- HPA-

1a $1 b \quad 2 a \quad 2 b \quad 3 a \quad 3 b \quad 5 a \quad 5 b$
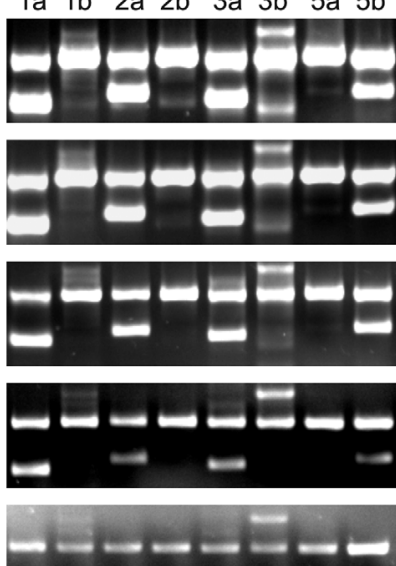

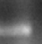

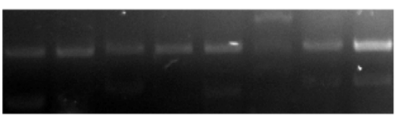

modified PCR-SSP
B

125

HPA- HPA- HPA- HPA-

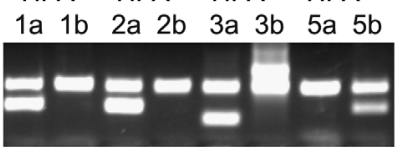

25

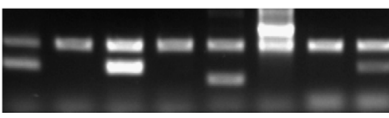

5

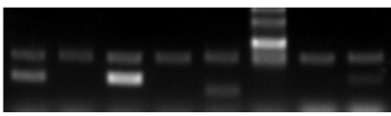

1

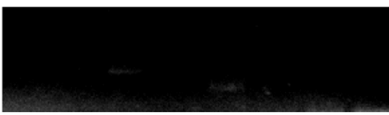

0.2

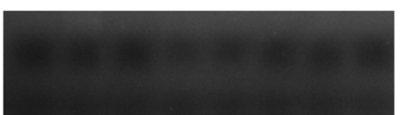

0.04

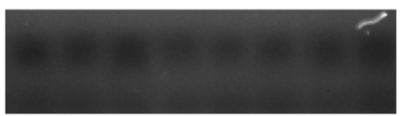

commercial PCR-SSP

Figure 2. Titration of the optimal range of template DNA concentration. A representative result from the genotyping of reference DNA3 using the modified (A) and the commercial PCR-SSP technique (B) is shown with given amounts of DNA per reaction. Approximately $1 \mathrm{ng}$ DNA per reaction was sufficient in the modified PCR-SSP technique, whereas at least $25 \mathrm{ng}$ DNA per reaction were needed for the commercial PCR-SSP technique.

HPA- HPA- HPA- HPA-

1a 1 b $2 a \quad 2 b \quad 3 a \quad 3 b \quad 5 a \quad 5 b$

A

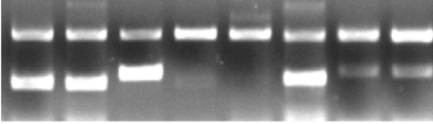

\section{$0.5 \mathrm{ml}$ amniotic fluid}

(week 16 of gestation)

B

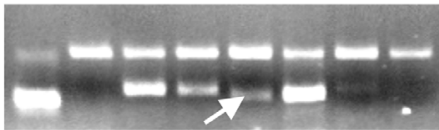

$1 \mathrm{ml}$ maternal plasma (week 40 of gestation)

C

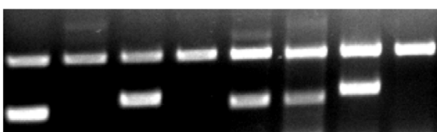

buccal swab

Figure 3. HPA genotyping of clinical samples with low DNA content. The representative results were obtained from samples with DNA concentrations of approximately $2 \mathrm{ng} / \mu \mathrm{L}$. (A) Fetal HPA genotypes could be identified from less than $0.5 \mathrm{~mL}$ amniotic fluid taken in week 16 of gestation only when the modified PCR-SSP technique was applied. (B) In one of the four maternal plasma samples, a mixed maternal/fetal HPA genotype was detectable. The fetal HPA-3a-specific PCR product is marked by a white arrow. (C) Unambiguous results could be obtained from buccal swab samples only using the modified PCR-SSP system. 


\section{Testing Clinical Samples with Low DNA Content}

Prenatal HPA typing for the diagnosis of NAIT is an important clinical application. Amniotic fluid represents a common source for fetal cells and is widely used for prenatal genetic testing (8). The PCR-SSP and PCR-ASO techniques have been applied for SNP typing without amniocyte culture (9-11). Especially in the early weeks of gestation, the amount of fetal DNA that can be extracted from amniotic fluid is low because of the limited volume of amniotic fluid and the limited number of fetal cells in the fluid sample. We investigated whether the modified PCR-SSP technique is suitable to obtain reliable typing results from amniotic fluid at the early weeks of gestation. DNA was extracted from two amniotic fluid samples that were both from week 16 of gestation. Accurate results that represented the fetal genotypes could be obtained from both samples (Figure 3A). The genotyping of the DNA samples using the commercial PCR-SSP system failed (data not shown).

Another source of fetal DNA for genetic testing is maternal plasma that had been used in prenatal genotyping for Rhesus antigens $(12,13)$. We investigated four samples of maternal plasma from weeks 38-40 of gestation. Previous genotyping of maternal leukocyte DNA and umbilical cord blood samples revealed fetal heterozygosity for one of the HPA-SNPs, whereas the maternal genotype was homozygous. Using the modified PCR-SSP technique, we could obtain a typing result from three of the four maternal plasma samples. In one plasma sample, no detectable amounts of DNA were found, and PCR-SSP typing failed. Only in one of the three cases where genotyping was successful could the fetus-specific allele be identified (Figure 3B). The commercial PCR-SSP kit failed to determine the genotypes from the plasma samples (data not shown). We conclude that the amount of DNA in plasma is individually different. Additionally, the maternal-to-fetal DNA ratio is variable and may be insufficient for prenatal SNP typing.

For a third example of samples with low DNA content, we investigated buccal swabs from eight healthy individuals. In forensic investigations, buccal swabs are often the source of DNA (14) and, usually, short tandem repeat (STR) polymorphisms are analyzed after PCR amplification. The genotyping of anonymous SNPs is regarded as an alternative method in the determination of individual identity (15). All eight samples revealed total amounts of DNA in the range of 300 $600 \mathrm{ng}$, with concentrations of 2-4 $\mathrm{ng} / \mu \mathrm{L}$. We could achieve typing results only when we used our modified PCRSSP technique and not the commercial PCR-SSP technique (Figure 3C). The HPA genotypes previously determined from the blood samples of these individuals were confirmed.

In general, $1 \mu \mathrm{M}$ allele-specific primer is suitable to increase the sensitivity of PCR-SSP techniques. We could demonstrate that approximately 1 ng DNA per allele-specific reaction was sufficient and, thus, 2 ng DNA were needed to obtain the genotype of a SNP. Applying our modified PCR-SSP technique, the genotype of 50 SNPs may be achieved from only $100 \mathrm{ng}$ DNA template.

\section{ACKNOWLEDGMENTS}

This work was supported by the 5th Framework Program "Quality of Life and Management of Living Resources" of the European Union (Platelet Diagnostics, QLK3-CT-2001-01169). We wish to thank Gabriele Rink for expert technical assistance.

\section{REFERENCES}

1.Welsh, K. and M. Bunce. 1999. Molecular typing for the MHC with PCR-SSP. Rev. Immunogenet. 1:157-176.

2.Hurd, C.M., G. Cavanagh, A. Schuh, W.H. Ouwehand, and P. Metcalfe. 2002. Genotyping for platelet-specific antigens: techniques for the detection of single nucleotide polymorphisms. Vox Sang. 83:1-12.

3.Santoso, S. and V. Kiefel. 1998. Human platelet specific alloantigens: update. Vox Sang. 74(Suppl 2):249-253.

4.Skogen, B., D.B. Bellissimo, M.J. Hessner, S. Santoso, R.H. Aster, P.J. Newman, J.G. McFarland. 1994. Rapid determination of platelet alloantigen genotypes by polymerase chain reaction using allele-specific primers. Transfusion 34:955-960.
5.Tanaka, S., A. Taniue, N. Nagao, S. Ohnoki, H. Shibata, Y. Okubo, and H. Yamaguchi. 1995. Simultaneous DNA typing of human platelet antigens 2, 3 and 4 by an allele-specific PCR method. Vox Sang. 68:225-230.

6.Klüter, H., K. Fehlau, S. Panzer, H. Kirchner, and G. Bein. 1996. Rapid typing for human platelet antigen systems-1, $-2,-3$ and -5 by PCR amplification with sequence specific primers. Vox Sang. 71:121-125.

7.Cavanagh, G., A. Dunn, C.E. Chapman, and P. Metcalfe. 1997. HPA genotyping by PCR sequence specific priming (PCR-SSP): a streamlined method for rapid routine investigations. Transfus. Med. 7:41-45.

8.Miny, P., S. Tercanli, and W. Holzgreve. 2002. Developments in laboratory techniques for prenatal diagnosis. Curr. Opin. Obstet. Gynecol. 14:161-168.

9.Bugert, P., W. Zieger, H. Klüter, and $\mathbf{H}$. Eichler. 2001. Prenatal HLA typing of uncultured amniocytes prior to the collection of related allogeneic cord blood. Tissue Antigens 58:103-106.

10.Eichler, H., A. Lese, J. Meckies, W. Zieger, H. Klüter, and P. Bugert. 2002. Prenatal HLA genotyping of uncultured amniotic fluid samples contaminated with maternal blood. Am. J. Obstet. Gynecol. 186:1366-1371.

11.McFarland, J.G., R.H. Aster, J.B. Bussel, J.G. Gianopoulos, R.S. Derbesand, and P.J. Newman. 1991. Prenatal diagnosis of neonatal alloimmune thrombocytopenia using allele-specific oligonucleotide probes. Blood 78:2276-2282.

12.Lo, Y.M. 1999. Fetal RhD genotyping from maternal plasma. Ann. Med. 31:308-312.

13.Legler, T.J., R. Lynen, J.H. Maas, G. Pindur, D. Kulenkampff, A. Suren, R. Osmers, and M. Köhler. 2002. Prediction of fetal Rh $\mathrm{D}$ and $\mathrm{Rh} \mathrm{CcEe}$ phenotype from maternal plasma with real-time polymerase chain reaction. Transfus. Apheresis Sci. 27:217-223.

14.Walsh, D.J., A.C. Corey, R.W. Cotton, L. Forman, G.L. Herrin Jr., C.J. Word, and D.D. Garner. 1992. Isolation of deoxyribonucleic acid (DNA) from saliva and forensic science samples containing saliva. J. Forensic Sci. 37:387-395

15.Gill, P. 2001. An assessment of the utility of single nucleotide polymorphisms (SNPs) for forensic purposes. Int. J. Legal Med. 114:204210 .

Received 13 March 2003; accepted 8 April 2003.

Address correspondence to Peter Bugert, Institut für Transfusionsmedizin und Immunologie, DRK-Blutspendedienst BadenWürttemberg - Hessen GmbH, FriedrichEbert-Straße 107, D-68167 Mannheim, Germany.e-mail:p.bugert@blutspende.de 